\title{
Carsten Wilke
}

Universidad de Duisburg, Alemania

\section{Materialidad y santificación de los libros según el misticismo judío medieval}

1. A los judíos se les suele llamar el "Pueblo del Libro" por una convención de lenguaje legada por el Alcorán, que resume bien la estrecha vinculación entre el judaísmo y la escritura en los niveles del culto, del imaginario religioso y de la vida cotidiana. Esta centralidad de la letra constituye el producto de un largo proceso histórico. Como se sabe, la vida intelectual que se refleja en las obras talmúdicas de la Baja Antigüedad está aún dominada por la dicotomía entre la lectura bíblica y la enseñanza del gran conjunto de la llamada "Ley Oral”, transmitida de maestro a discípulo. En seguida, la historia ha redistribuído varias veces las relaciones jerárquicas entre los diferentes vehículos de la tradición: la voz viva, la imagen y finalmente la letra, de la cual hablaremos aquí.

La observación establecida por recientes estudios en la historia del libro según la cual la extensión del uso de la escritura constituye una de las evoluciones socio-culturales más importantes de la Alta Edad Media vale también para el judaísmo. ${ }^{1}$ Evidentemente, las condiciones sociales se presentan de una

${ }^{1}$ De los países europeos, los más antiguos manuscritos hebreos que presentan una fecha nos llegan del siglo XI, su número aumenta progresivamente a partir de este tiempo, presentando una alza súbita a mediados del siglo xIII. Véase Colette Sirat, Du scribe au livre: les manuscrits hébreux du Moyen Âge, París, CNRS Editions, 1994, p. 12. 
manera muy distinta según las comunidades religiosas. En el ambiente cristiano, las cancillerías y los conventos alimentan la difusión del libro entre una élite de letrados normalmente ligados al poder real o eclesiástico. Los manuscritos hebreos, por su parte, son objetos domésticos que deben su existencia a actores individuales: copistas, encuadernadores, mecenas, propietarios privados y herederos cuya actividad está motivada por una ética religiosa fuera de toda coordinación política o administrativa. La difusión de la literatura, que se refleja en la multiplicación de los códices, no es un probleina meramente literario ni se puede ligar únicamente a evoluciones técnicas y sociales. Esta difusión atañe también al lugar que la escritura llegó a ocupar en las ideas y mentalidades religiosas.

Intentaré explorar esta dimensión espiritual con respecto al conjunto de preceptos y exempla éticos que se conoce bajo el nombre de Sefer Jasidim o "Libro de los Devotos". ${ }^{2}$ Este libro, de marcado tono ascético, reúne las máximas de un grupo místico judío que floreció en los siglos XII-XIV en las ciudades imperiales del Rin. ${ }^{3}$ Para evitar malentendidos, hay que advertir que estos jasidim o "Devotos" medievales no tienen ninguna relación con el movimiento jasídico que surgió entre los judíos de la Europa del Este en la época contemporánea. El personaje del jasid - aquél que guarda un respeto extremo hacia los preceptos rituales, morales y comunitarios del judaísmo- ha existido en la espiritualidad judaica de todos los tiempos. Al lado de muchos detalles concretos que este libro revela sobre la civilización del libro en la Edad Media, él nos ayuda sobre

2 Para un estudio de las formas narrativas, véase Eli Yassif, "Entre culture populaire et culture savante; les 'exempla' dans le 'Sefer Hassidim' ", AnnalesHistoire, Sciences Sociales 49, 5, 1994, pp. 1197-1222.

${ }^{3}$ Desde la primera edición (1538), el Sefer Jasidim se ha impreso normalmente en una versión corta, de la cual Rubén Margoliut realizó una edición científica (Jerusalén, 1957). Un manuscrito de la Biblioteca palatina de Parma conserva una versión mucho más completa; este texto fue editado por J. Wistinetsky (Berlín, 1891). Citamos estas dos ediciones distinguiéndolas con las siglas $\mathrm{M} \mathrm{y} \mathrm{W}$, seguidas por el número de párrafo. 
todo a comprender el lugar ideal asignado al libro en la mentalidad religiosa. ${ }^{4}$

2. Para los autores, como para todos los místicos judíos, la letra hebrea es una realidad divina que precede a la creación del mundo. En cuanto objeto material, el libro se integra en lo alto de una jerarquía de los objetos sagrados la cual se determina por una serie de situaciones hipotéticas: si un incendio amenaza tu habitación, ¿cuál objeto salvarás primero? Si por necesidad estás forzado a vender tus posesiones, ¿cuál será el bien que intentarás conservar hasta el final? La respuesta es unívoca: el objeto más sagrado que puede encontrarse en posesión de un judío medieval es siempre el libro (W691=M1023; W1749a).

Las fuentes talmúdicas ofrecen ya disposiciones similares. Sin embargo, éstas se refieren casi siempre al rollo del Pentateuco que tiene un papel destacado en la liturgia sinagogal. Por su parte, los medievales transportan estas reglas a una categoría de libros que el Talmud aún no mencionaba: los códices que cada uno estudia en su habitación particular y que contienen textos tanto bíblicos como recientes. Naturalmente, surgen así nuevas problemáticas, pues el libro aparece inmerso en las circunstancias de la vida física, psicológica, económica, conyugal y familiar de su propietario.

Muchas de estas reglas manifiestan la intención de recomendar ampliamente y de manera pragmática la producción cuidadosa y el estudio diligente de los manuscritos. ${ }^{5}$ Pero no es sola-

\footnotetext{
${ }^{4}$ Reunir y traducir un conjunto de fuentes para la Historia del Libro de las diferentes redacciones del Sefer Jasidim ha sido el objetivo de un grupo de investigación encabezado por Colette Sirat, catedrática de Paleografía Hebrea en París, con quien tuve la oportunidad de trabajar durante algunos años. Mis observaciones se fundan en este trabajo colectivo, cuyo resultado fue la publicación francesa $\mathrm{La}$ Conception du livre chez les piétistes ashkénazes, por Colette Sirat y Michèle Dukan, Claude Heymann, Carsten L. Wilke, Monique Zerdoun, Ginebra, Droz, 1996 (Col. Histoire et civilisation du livre, no. 23).

5 Malachi Beit-Arié, "Ideals versus Reality. Scribal Prescriptions in 'Sefer Hasidim' and Contemporary Scribal Practices in Franco-German Manuscripts”,
} 
mente a causa de su función que se le debe veneración al libro. $\mathrm{Su}$ manipulación es un ceremonial simbólico que confiere a este objeto un grado de santidad particular. El honor del libro estaría amenazado por un eventual contacto físico con ambientes sucios o indecentes: está prohibido ponerlo en el suelo tomarlo con la mano izquierda (W693=M109), peinarse el cabello o la barba por encima de él, etc. (M101; Wó56=M912). Una manifestación de "menosprecio al libro" —así lo llaman los Devotos en su lenguaje - es también servirse de él para cualquier uso diferente al de la lectura y del estudio, por ejemplo, para esconder dinero (W663=M907) o para protegerse del sol, del humo o de miradas indiscretas (W659=M904).

Así como un contacto indecente puede ofender la santidad del libro, esta última tiene la capacidad de contagiar los materiales de su ambiente (W1157, M893), como si el libro desplegara una especie de aura de santidad alrededor de sí. El pergamino, el cálamo y la tinta se santifican no sólo por el contacto con la letra sagrada, sino incluso por la intención de hacerlos servir a tal propósito; estos objetos piden entonces una atención ritual no menor que los libros mismos. Una deferencia particular se exige tanto para el pergamino destinado a escribir un texto sagrado (W699a, M141a; W700=M281a), como para el cálamo con que se escribe (W1754-1755b=M894), pero más aún para la tinta que está destinada a tal uso (W724-726= M888; W730=M889, W714=M890; W404=M771; W1758). Hay que abstenerse de aplicar a usos profanos incluso el agua destinada para diluir esta tinta, y el vaso que sirve para cargar esta agua (W729=M889).

Tanto el libro como sus materiales se contagian del carácter y de los pensamientos del hombre que los produce y maneja. Por lo tanto, se exige al copista que dirija su pensamiento hacia Dios (W702b=M883); de no hacerlo, sus deseos, rencores y

Rashi, 1040-1990: hommage à Ephraim E. Urbach. Actes du IVe Congrès européen des Études juives, ed. Gabrielle Sed-Rajna, París, Cerf, 1993, pp. 559-566. 
pensamientos profanos infectarían su letra y causarían daños a aquel que estudie o rece en el libro escrito así (W405a=M249; W1621). La exigencia de una correcta disposición mental ( $k a-$ vaná) justifica que una mujer - aunque tenga hermosa letrano deba copiar un Rollo del Pentateuco, porque su poca instrucción religiosa no le permitiría entender plenamente ell texto (W702a).

Para los místicos judíos, el complejo del "menosprecio al libro" comprende también ofensas mentales y verbales: aunque un libro esté lleno de errores del copista, nunca hay que decir que no vale más que para ser quemado $y$, cuando uno quiere comprar un libro, no debe hablar mal de él para que el vendedor baje el precio. Es verdad que los libros pueden ser vendidos y comprados, pero nunca hay que comparar verbalmente su valor con el de otro objeto. Por ejemplo, cuando dos hijos comparten una herencia, sería al extremo indecente decir: toma tú tal libro y yo tomaré tal perro', o 'tal letrina', o 'tal saco de oro', o 'tal libro cristiano' (W658a=M913).

Vemos enumerados aquí los cuatro polos que en el mundo profano se confrontan a la santidad del libro: el sexo (al cual hace alusión el motivo bíblico del perro), ${ }^{6}$ el excremento, el dinero y el cristianismo. Observemos unos ejemplos.

En la casa ideal de los Devotos existe una separación estricta entre las prácticas literarias y los actos u objetos sexualmente connotados. ${ }^{7}$ El lugar antitético del libro es la cama conyugal, sobre la cual nunca hay que poner un libro ni leer sentado en ella (W640). No sería menos indecente aparecer desnudo frente a un libro (W651; W459=486a; W648). El rito de lavarse las manos es el pasaje obligatorio entre el mundo del sexo y el mundo del libro (W639b=M274; W1609).

\footnotetext{
6 Según Deuteronomio XXIII,18: "No traerás a la casa del Señor tu Dios el sabrio de una prostituta ni el precio de un perro".

7 Judith R. Baskin, "From Separation to Displacement: the Problem of Women in 'Sefer Hasidim' ", AJS Review 19, 1, 1994, pp. 1-18.
} 
El mismo rito se impone después de haber hecho las necesidades físicas (W1066). Los Devotos recomiendan también a los que sufren de flatulencia cubrir sus libros durante la noche para no insultarlos con sus vientos gástricos (W1741b=M917).

En tercer lugar, el mundo profano y anti-literario está determinado por el dinero y su lógica. Respecto al libro, la idea principal es que hay que seguir la jerarquía de las santidades y no la jerarquía de la mercancía. Por ser más sagrado, un simple ejemplar del Pentateuco debería ser tratado con más respeto que una copia entera del inmenso Talmud (W666-667=M928929).

Finalmente, el mundo de la impureza contiene las manifestaciones de la "idolatría", es decir —en el pensamiento de los judíos medievales- el culto cristiano (W993). Uno entiende el desafío particular que constituye la cultura literaria latina, cuyos productos se parecen externamente a los libros hebreos. Cierto, los judíos entendían tan poco latín como los cristianos sabían hebreo. Pero un libro era un objeto de valor que servía, como diríamos hoy, para invertir dinero, y varias veces cristianos dejaron sus libros en depósito para obtener un préstamo de un judío. El Sefer Jasidim confirma que, de este modo, incluso un Devoto podía tener un libro latino en su casa. Definía a este objeto entonces con el calificativo hebreo de pasul, que es antónimo de casher y significa que un objeto es ritualmente inadaptado para servir su propósito natural. El libro en latín es un libro que no sirve para la lectura, una especie de simulacro de un libro. No hay que poner libros latinos y hebreos en la misma caja, ni compararlos de cualquier modo; por ejemplo, cuando uno carga libros en un burro, no hay que meter el libro hebreo en la bolsa de un lado del animal y el libro en latín en la del otro para que haga el contrapeso (W668b, M913b).

Los radicales de la corriente devota eran de la opinión de que uno no debe dar ningún libro a un cristiano, porque éste va inevitablemente a tratarlo con menosprecio. Otros suponen que 
un judío puede recurrir a los servicios de un encuadernador cristiano, a condición de vigilar que el artesano no reutilice en su taller los márgenes cortados del pergamino (W682b=M280). Inversamente, el pergamino de un libro cristiano de ningún modo puede ser reutilizado para un libro judío, sin importar que el texto en latín sea de carácter no religioso, ni que el judío haya borrado la escritura. Si, por alguna coincidencia, un judío llega a poseer un libro cristiano definitivamente, tiene que quemarlo (W405b=M249b, M141d).

3. El razonamiento casuístico que hemos encontrado aquí está lejos de las abstracciones escolásticas tan presentes en el mundo intelectual cristiano de la misma época. La abstracción busca un lenguaje común entre adherentes de diferentes tradiciones e intereses, el razonamiento de tipo jurídico se queda en el interior de la propia tradición, pero busca el diálogo entre las condiciones del presente y las autoridades del pasado. Para reglamentar el uso generalizado del libro, el judío medieval tenía que establecer derivaciones y analogías complejas que permitían atribuir fuentes bíblicas o talmúdicas a este fenómeno nuevo.

Ya hemos mencionado el procedimiento que consiste en despojar de su contexto litúrgico habitual las reglas sobre el Rollo del Pentateuco, lo que permite aplicar muchas disposiciones que guían el oficio sinagogal al uso personal de los códices en el hogar. Así, los rituales acerca de la escritura se encuentran, con cierto modo, privatizados.

Las distinciones que el Talmud observa entre el Pentateuco y las otras partes de la Biblia se aplican entonces a la jerarquía entre textos bíblicos y rabínicos (W603; W699=M141b), pero en la Edad Media se transforma incluso la idea misma de una jerarquía entre los libros: un libro no puede servir a otro como pasa en el Talmud; se considera indecente emplear un libro para reglar un pergamino o para marcar las líneas de su modelo mientras uno está copiando (M101, 898; W661=M902; W646= 
M908). La regla de que "un libro no debe servir a otro libro" (W1748b-c=M903a) manifiesta la idea de que ningún libro admite una finalidad que le sea externa.

La reinterpretación de la fuente talmúdica no es un procedimiento completamente nuevo; gracias a tales artificios hermenéuticos la tradición judía ha podido readaptar varias veces su idea de la escritura sagrada a las diferentes materializaciones históricas: de las tablas de Moisés al Rollo litúrgico del Pentateuco del cual trata el Talmud, hasta los códices medievales. Esta larga historia de las actualizaciones hermenéuticas permite que los Devotos se refieran directamente al culto del Templo para justificar, por analogía, la prohibición de manejar libros junto con alimentos (W658=M910c) u otras decisiones semejantes.

Miremos un razonamiento típico de este género: cuenta la leyenda que, antes de la destrucción del Templo, el profeta Jeremías salvó el arca divina con las tablas de Moisés y la escondió en la caverna de un monte. El Talmud añade que un anciano fue castigado con la muerte porque, en un intento de descubrir el escondite, cortó los árboles que habían crecido por encima de la caverna (Talmud de Babilonia, Yoma 54²). Nuestros jasidim recuerdan esta leyenda para prohibir que alguien tenga su biblioteca en la planta baja de su casa mientras duerme en la planta alta. Uno adivina fácilmente la analogía, no desprovista de humor, que se establece entre el transgresor talmúdico cortando sus árboles y el anciano medieval que rinde sus ojos a un sueño tal vez un poco ruidoso (W1638/M812).

La deducción intertextual establece un paralelismo, pues, no solamente entre el códice medieval y las tablas de Moisés, sino también entre el cofre donde el judío tenía su biblioteca y el arca del Templo. Más aún, se compara la lectura con el sacrificio mismo. La preocupación por el honor del libro apela a las leyes bíblicas que conciernen la integridad de la ofrenda y del mismo altar de sacrificio; por consiguiente, muchas veces la 
escritura de los manuscritos se pone en analogía con la construcción del Templo de Jerusalén (W726=M888; W680=M279; W628).

Otro modo de llenar de significado religioso la vida literaria consiste en humanizar el libro. Pero en el lenguaje metafórico, el libro nunca es un niño como para nosotros, sino un anciano. Se nota fácilmente que la comparación entre el libro y el cuerpo humano se funda en la idea de que ambos son capaces de sufrir y de exigir un gesto solidario. Por ejemplo, las normas que se aplican al rescate de correligionarios secuestrados determinan también las pautas para el rescate de libros robados: así como un sabio de gran originalidad tiene preferencia entre otros para ser rescatado, también un manuscrito único justifica más gastos y esfuerzos (W1748a=M926).

Dentro de este complejo antropomórfico, el espejismo entre el libro y el cuerpo muerto está particularmente marcado. Una ley talmúdica impone el silencio completo a quien está transportando a un muerto. Los Devotos medievales opinan que esta regla vale también para quien está cargando un libro (W339= M741; M97).

La analogía entre el libro y el cadáver define la cultura del libro como un reflejo de las prácticas rituales que según la ley rabínica se deben a los muertos. Todo un interesantísimo capítulo del Sefer Jasidim explora esta afinidad entre el estudio y el luto. Los autores parten de la observación de que hay tratados talmúdicos que "viven" gracias a su constante aplicación en la jurisprudencia, mientras que los tratados sobre los sacrificios del Templo o la agricultura en la Tierra Santa son como "muertos". Los místicos suponen que estos libros exigen ser estudiados con una deferencia semejante a la que se debe a una persona muerta. Pero, ¡cuidado!, el estudio de un texto "muerto", al igual que el luto, expone el hombre a la proximidad del ángel de la muerte y uno debe proceder con precauciones particulares para superar este peligro (W588). 
Un libro particular puede ser una extrapolación de la personalidad de su lector. Las lecturas de un hombre, creen los místicos, revelan lo que está escondido en su corazón (W291). La correspondencia entre lo escrito y el orden moral es tan estrecha que se cree que portar un libro de cabeza puede provocar un desorden sicológico (M943-944=W754). Aun muerto, el hombre judío aparece como inseparable de su libro, porque en el otro mundo, las almas pasan la eternidad estudiando de la misma manera en que lo hicieron cuando estaban vivos (W141). Asimismo, estudiar un libro que ha sido escrito o poseído por una persona ya muerta se considera como una buena obra que elevará los méritos del difunto en el más allá (W355=M747).

Aunque la posesión de los libros y las demás prácticas literarias sean actos íntimamente personales, el libro nunca pierde su personalidad autónoma. Polemizando contra el orgullo individual que las escuelas rabínicas del siglo XII habían generado entre los talmudistas, los Devotos recuerdan repetidas veces que nadie, ya sea autor, copista o dueño, debe proyectar su personalidad en el interior del libro marcándole su nombre u otro aditamento personal. Los místicos exigen el anonimato de los autores (W746, W1945b), los copistas (W700b=M281b; W706=M136; W1620) y los propietarios (W707, 1750). No se deben añadir al texto notas profanas (W645b=M898b, $\mathrm{W} 1747 \mathrm{~b}=\mathrm{M} 607$ ) y ni siquiera bendiciones devotas (W703a, W705, 731b, 1726b, M884).

4. Hemos visto que, en el imaginario religioso de los jasidim, el libro se erige como un santuario comparable al Templo, adquiere una personalidad autónoma cuya creación, vida, sufrimiento y muerte deben ser respetados en todas las circunstancias. A veces, las reglas sobre la manipulación del manuscrito hacen pensar en las tradiciones cristianas con respecto al Corpus Dei. Si bien el judaísmo nunca ha santificado la escritura, nunca la ha convertido en sacramento, ni la ha apartado 
de su función. En casos de conflicto, casi todas las pautas de respeto pueden ser suprimidas o ignoradas si se está arriesgando la finalidad del libro. A pesar de toda su veneración por el libro, los Devotos permiten que, si uno teme que le hurten su libro durante un viaje, mande su libro con un cristiano. Incluso, si va en burro, puede intentar esconder el libro sentándose encima de él (W1848). Cuando un judío encuentra en el mercado un libro hebreo robado, entonces puede y hasta debe hablar de este libro con todo su desdén para rescatarlo a bajo precio (W665a=M925). En contradicción consciente con lo dicho sobre la jerarquía de las santidades, ciertos contextos exigen que se acuerde una preferencia a libros menos santos, pero más originales, como lo hemos visto en el caso del rescate de libros hurtados (W664=M925).

Para los místicos renanos, la difusión de un libro para el estudio es más importante que su conservación. Todo dueño de una biblioteca - hacen hincapié estos místicos- tiene la obligación religiosa de prestar sus libros para que sus correligionarios los estudien y los copien, aun sabiendo que los libros pueden sufrir daños (W1470, M877). Hay que prestar los libros, de preferencia, a la gente pobre, e incluso si uno se enemista con su vecino, debe seguir prestándole sus libros (W676=M871). Los autores están persuadidos de que precisamente el propietario que no presta sus libros tendrá por castigo que su biblioteca se incendie o que sus hijos la desbaraten después de su muerte (W673=M869). Los Devotos muestran un conocimento desengañado sobre la vida de los libros: ningún libro dura eternamente; lo mejor que uno puede hacer es utilizarlo bien y procurarle una amplia difusión.

Nos damos cuenta que, a pesar de su gran veneración por los libros, los místicos no los han transformado en ídolos ni en fetiches. El libro sagrado no es una bandera por la cual uno debe sacrificar su vida. Lo recuerda el caso hipotético del incendio: cuando las llamas están apoderándose de una habita- 
ción llena de libros donde yace un muerto, uno tiene la obligación de salvar el cadáver y dejar quemar los libros; y si se encuentra además un niño, hay que salvarlo primero (M724). Los libros parecen aquí menos sagrados que los difuntos, y mucho menos que las vidas humanas.

En un caso ficticio, se salva una vida gracias al abuso o "menosprecio" de un libro: si un discípulo teme por su vida al ser golpeado por su cruel maestro, puede utilizar su libro para protegerse (W662=M276). Vemos que el bien de los seres humanos puede suspender los tabúes que los Devotos erigieron con tanta insistencia. Cuando un niño que aún no alcanza la edad de la razón comete el acto, en sí sacrílego, de defecar frente a un libro, está prohibido castigarlo, porque el niño angustiado sufriría retención y se pondría en peligro su salud (W683= M919). A pesar de todas las reservas que se formulan contra la cosificación comercial de los libros, un Devoto llamado a estimar el precio de un libro debe suspender su estudio religioso y proceder con toda conciencia a esta tarea mercantil, para que el pobre que está obligado a vender su libro no padezca tanto daño en sus bienes (W1226, M1060). Miremos finalmente un caso en que los Devotos inventan un conflicto entre el libro y el sexo: presentan a una mujer cuyo marido no quiere cumplir con su obligación religiosa de comprar libros y de dar limosna a los pobres; ella le anuncia que, hasta que cambie su conducta, ella dejará de ir al baño ritual, impidiendo así las relaciones sexuales. Cuando el marido se queja delante de un sabio, éste alaba la decisión de la mujer, pero en seguida habla con la mujer a solas, diciéndole que persigue un buen fin con medios impropios: al prolongarse la huelga sexual, su marido se quedaría con tentaciones peligrosas y ella sin hijos, cosas que ni siquiera el bien de los libros justifica (W670=M873).

Un último caso resume el valor supremo, pero no ilimitado, que el libro tiene en la espiritualidad de nuestros místicos. Una vez, un Devoto hablaba con unos judíos que se disponían a re- 
cibir el bautismo. Todos sus esfuerzos de disuasión habían sido vanos hasta que se valió del último medio para enseñarles la significación de su apostasía: toma el Rollo sagrado del Pentateuco y lo arroja al suelo ante el asombro de sus interlocutorios (W125b). Vemos, en este momento excepcional, que el respeto hacia el libro, o más exactamente el terror de verlo profanado, se ha hecho el sentimiento más íntimo de pertenencia a la religión judía, un sentimiento experimentado aún por el casi apóstata. Pero el mismo acontecimiento nos muestra que el místico judío reconoce un "más allá" del libro, un punto de vista capaz de justificar incluso la violación consciente y calculada de este santuario de pergamino. Aun el inmenso peso de este símbolo religioso pierde valor delante del respeto debido a la vida humana y a la sobrevivencia de la comunidad. 